\title{
Preparation of Calcium Alginate-Tetrandrine Beads Using Ionic Gelation Method as Colon-Targeted Dosage Form
}

\author{
Raditya Iswandana ${ }^{1, *}$, Kurnia Sari Setio Putri', Fitri Rina Wulandari', Ghaathy Najuda', Santi Purna Sari', \\ Joshita Djajadisastra $^{1}$ \\ ${ }^{1}$ Laboratory of Pharmaceutical Formulation and Development, Faculty of Pharmacy, Universitas Indonesia, Depok, 16424, Indonesia. \\ ${ }^{2}$ Laboratory of Pharmacology and Toxicology, Faculty of Pharmacy, Universitas Indonesia, Depok, 16424, Indonesia.
}

\begin{tabular}{|c|c|}
\hline ARTICLE INFO & ABSTRACT \\
\hline $\begin{array}{l}\text { Article history: } \\
\text { Received on: } 05 / 02 / 2018 \\
\text { Accepted on: } 16 / 03 / 2018 \\
\text { Available online: } 30 / 05 / 2018\end{array}$ & $\begin{array}{l}\text { Colon drug delivery systems are widely used to deliver active substances and provide better therapeutic effects to the } \\
\text { site of disease in the colon, i.e., treatment for intestinal fibrosis. In this study, we aimed to formulate tetrandrine into } \\
\text { calcium-alginate beads coated by Hydroxypropylmethyl Cellulose Phthalate (HPMCP), Cellulose Acetate Phthalate } \\
\text { (CAP), Eudragit L100-55 or Eudragit L100 as colon targeted dosage to provide better antifibrosis effect at the site } \\
\text { of disease. Among dosage forms, beads provide some advantages for colon drug delivery system, especially for its }\end{array}$ \\
\hline $\begin{array}{l}\text { Key words: } \\
\text { Beads, tetrandrine, calcium } \\
\text { alginate, ionic gelation, } \\
\text { colon-targeted. }\end{array}$ & $\begin{array}{l}\text { flexibility in dosing. Calcium alginate-tetrandrine beads were prepared in three formulae with various concentrations } \\
\text { of calcium chloride as a crosslinking agent }(2 \%, 3 \% \text {, and } 4 \%) \text {. All formulae were characterized by its morphology, } \\
\text { particle size, moisture content, process yield, entrapment efficiency, thermal character, crystallinity, and swelling. The } \\
\text { obtained beads possessed almost spherical and particle size distribution of } 742.753-780.683 \mu \text { m. Formula } 2 \text {, with a } \\
\text { ratio of sodium alginate and } \mathrm{CaCl}_{2} 2: 3 \text {, showed the best entrapment efficiency of } 82.46 \pm 2.73 \% \text {. Formula } 2 \text { was then } \\
\text { coated with HPMCP HP-55, CAP, Eudragit L100-55 or Eudragit L100 and measured for its drug release profile in- } \\
\text { vitro. The results showed that the beads which were coated with } 10 \% \text { CAP were able to hold the drug released in the } \\
\text { gastric and provide better released of tetrandrine in the colon condition }(67.68 \%) \text {. This result also confirmed with the } \\
\text { in-vivo test. Beads which were coated by CAP } 10 \% \text { could be found in the rat intestine. }\end{array}$ \\
\hline
\end{tabular}

\section{INTRODUCTION}

Fibrosis is a disease associated with chronic injury and inflammation within an organ, which is characterized by progressive and irreversible destruction of the normal architecture of an organ by excessive deposition of extracellular matrix (ECM), and ultimately leads to organ malfunction and death. To date, there are no effective therapies to stop or reverse fibrosis development, and it is estimated that fibrosis contributes to $45 \%$ of deaths in the United States (Adhyatmika et al., 2015). Fibrosis is the result of a chronic inflammatory reaction that stimulated by infection, autoimmune reactions, allergic responses, chemicals, radiation, and injury to the tissue (Speca et al., 2012). Intestinal fibrosis is

\footnotetext{
${ }^{*}$ Corresponding Author

Raditya Iswandana, Laboratory of Pharmaceutical Formulation and Development, Faculty of Pharmacy, Universitas Indonesia, Depok, 16424, Indonesia. E-mail: raditya@farmasi.ui.ac.id
}

found in most patients with inflammatory bowel disease (IBD), which affects at least 2.2 million Europeans (Loftus, 2004). To date, the only available treatment for intestinal fibrosis is surgery. Therefore there is an urgent need for alternative and effective treatment modalities.

Currently, there are several antifibrotic compounds under research, such as galunisertib (Luangmonkong et al., 2015), rosmarinic acid (Iswandana et al., 2016), and tetrandrine. In this study, tetrandrine was used as an antifibrotic drug model. Tetrandrine can inhibit the growth of hypertrophic scar-derived fibroblasts (HSFs) through increased and decreased Smad7 Smad2 resulting in inhibition of transcription of TGF- $\beta 1$ and its intracellular signaling pathways. This result indicated that tetrandrine could be used to prevent and treat scar tissue in fibrosis (Lin et al., 2012).

Colon drug delivery systems offer some advantages for colon fibrosis treatment: deliver the drugs to site of disease 
in the colon, preserve the stability of the drugs throughout the GIT, prevent the drugs to be released and degraded in the upper gastrointestinal tract, and thus provide better therapeutic effects in the colon (Wynn, 2008; Philip and Philip, 2010; Rathbone et al., 2003). Among dosage forms, beads provide some advantages for colon drug delivery system, especially for its flexibility in dosing (Amidon et al., 2015).

Sodium alginate is a biocompatible and non-toxic polymer, which widely used as a matrix for several dosage forms (Shukla and Tiwari, 2012; Biswas and Sahoo, 2016). In this study, sodium alginate was used as a beads-forming polymer due to its capability to form a water-insoluble matrix with divalent ions $\left(\mathrm{Ca}^{2+}\right)$ by the cross-linking process of ionic gelation method (Shukla and Tiwari, 2012). HPMCP (Hydroxypropylmethyl Cellulose Phthalate) HP-55, CAP (Cellulose Acetate Phthalate), Eudragit L100-55 or Eudragit L100 were used to coat the calcium alginate beads, to improve beads ability to prevent drug release in upper gastrointestinal tract (Rowe et al., 2009).

This study was performed to prepare colon-targeted beads using ionic gelation method and determine its morphology, particle size, moisture content, process yield, entrapment efficiency, thermal character, crystallinity, and swelling. The obtained beads with the highest entrapment efficiency were then coated with a pH-sensitive polymer (HPMCP HP-55, CAP, Eudragit L100-55 or Eudragit L100) and evaluated for its dissolution profile in medium with GIT condition and its in-vivo targeting test.

\section{MATERIALS AND METHODS}

\section{Materials}

Sodium alginate (Brataco, Indonesia), tetrandrine (Shaanxi Ciyuan Biotech, China), tetrandrine standard (Sigma Aldrich, Singapore), calcium chloride (Merck, Germany), HPMCP HP-55 (Shinetsu, Japan), CAP (Eastman, Singapore), Eudragit L100-55 (Evonik, Indonesia; obtained from PT Jebsen Jessen Ingredients, Indonesia), Eudragit L100 (Evonik, Indonesia; obtained from PT Jebsen Jessen Ingredients, Indonesia), triethyl citrate (Weifang Limin Chemical, China; obtained from PT Lawsim Zecha, Indonesia), talc (Brataco, Indonesia), acetone (Brataco, Indonesia), isopropanol (Mitsui Chemical, Japan), hydrochloric acid (Merck, Germany), potassium phosphate monobasic (Merck, Germany), and sodium hydroxide (Merck, Germany).

Animals: Sprague-Dawley male rats with a weight of 200-250 g (Balitbangkes, Indonesia).

\section{Preparation of calcium alginate beads}

Ionic gelation method was utilized to prepare the calcium alginate beads. Sodium alginate solution $2 \%(\mathrm{w} / \mathrm{v})$ in deionized water was mixed with tetrandrine solution in $\mathrm{HCl} 0.1 \mathrm{~N}$. The mixture was then dripped into $3 \%$ calcium chloride solution and stirred at $200 \mathrm{rpm}$ using a magnetic stirrer. The obtained beads in chloride solution could stand for $15 \mathrm{~min}$ after the reaction has completed. All formulae for calcium alginate beads preparation can be seen in Table 1 .

Table 1: Calcium alginate beads formula.

\begin{tabular}{ccccc}
\hline Formula & $\begin{array}{c}\text { Sodium Alginate } \\
(\% \mathbf{w} / \mathbf{v})\end{array}$ & $\begin{array}{c}\text { Calcium chloride } \\
(\% \mathbf{w} / \mathbf{v})\end{array}$ & $\begin{array}{c}\text { Tetrandrine } \\
(\% \mathbf{w} / \mathbf{w})^{*}\end{array}$ & $\begin{array}{c}\text { Crosslink } \\
\text { time }(\mathbf{m i n})\end{array}$ \\
\hline 1 & 2 & 2 & 1 & 15 \\
2 & 2 & 3 & 1 & 15 \\
3 & 2 & 4 & 1 & 15 \\
\hline
\end{tabular}

*Weight ratio between sodium alginate and tetrandrine $(2: 1)$.

The beads were separated from the solution and rinsed with deionized water at least three times and dried at room temperature. The dried beads were then characterized (for its shape and morphology, particle size distribution, yield, entrapment efficiency, and moisture content) before it was coated.

\section{Beads coating}

Calcium alginate beads were coated by pouring \pm 100 $\mathrm{mg}$ dry beads into the coating solution (HPMCP HP-55, CAP, Eudragit L100-55 or Eudragit L100), then and dried at $55^{\circ} \mathrm{C}$. For HPMCP, a $10 \%(\mathrm{w} / \mathrm{v})$ and $12 \%(\mathrm{w} / \mathrm{v})$ solution in acetone were used and triethyl citrate $(2.5 \%, \mathrm{w} / \mathrm{w})$ was used as a plasticizer. In the case of CAP, a $10 \%(\mathrm{w} / \mathrm{v})$ and $15 \%(\mathrm{w} / \mathrm{v})$ solution in acetone were used for coating and triethyl citrate $(2.5 \%, \mathrm{w} / \mathrm{w})$ was used as a plasticizer. Next, Eudragit L100-55 was mixed with the plasticizer and talc thus can be obtained a $10 \%$ and $12.5 \%$. The plasticizer used was triethyl citrate in $2.5 \%$ or $3.125 \%(\mathrm{w} / \mathrm{w})$ concentration of Eudragit L100-55. All coating materials then dissolved in acetone: isopropanol $(1: 1)$. Beads which would be coated were added to Eudragit L100-55 solutions while stirred. The similar method was performed with Eudragit L100. The coating process was repeated until the weight of the beads increases for 33\%. Beads coating formula can be seen in Table 2 .

Table 2: Coating formula.

\begin{tabular}{cccccc}
\hline Formula & Coating Material & \% w/v & Plasticizer (\%)* & Talc (\%)* & Solvent \\
\hline A & HPMCP & 10 & 2.5 & 5 & Acetone \\
B & HPMCP & 12 & 2.5 & 5 & Acetone \\
C & CAP & 10 & 2.5 & 5 & Acetone \\
D & CAP & 15 & 2.5 & 5 & Acetone \\
E & Eudragit L100-55 & 10 & 2.5 & 5 & Acetone-Isopropanol (1:1) \\
F & Eudragit L100-55 & 12.5 & 3.125 & 6.25 & Acetone-Isopropanol (1:1) \\
G & Eudragit L100 & 10 & 2.5 & 5 & Acetone-Isopropanol (1:1) \\
H & Eudragit L100 & 12.5 & 3.125 & 6.25 & Acetone-Isopropanol (1:1) \\
\hline
\end{tabular}

*Calculated based on coating concentration and solvent. 


\section{Physical characterization}

Beads were observed for its color, smell, shape, and texture of the surface visually by using an optical microscope. Before and after coated, the diameter of the beads was measured using an optical microscope. The morphology of the beads was observed using a scanning electron microscope (SEM, LEO 420i, England).

The moisture content of the beads was determined by using a moisture analyzer (Adam, USA) by heating one gram of beads at $115^{\circ} \mathrm{C}$. Thermal property of the beads was observed using a differential scanning calorimeter (DSC, Perkin Elmer type 8000, USA). The sample was heated at a temperature of $30^{\circ} \mathrm{C}-350^{\circ} \mathrm{C}$, with a heating rate of $10^{\circ} \mathrm{C}$ per min. The crystallinity of the beads was measured by X-ray diffractometer (Philips PW-1710, The Netherlands) at a voltage of $30 \mathrm{kV}, 15 \mathrm{~mA}$ current.

\section{Process yield}

The process yield was calculated by comparing the total weight of the obtained dry beads to the total of raw materials used during preparation:

$$
\text { Process yield }=\frac{\mathrm{Wm}}{\mathrm{Wt}} \times 100
$$

where $\mathrm{Wm}=$ the weight of final beads $(\mathrm{g})$ and $\mathrm{Wt}=$ total weight of initial beads material $(\mathrm{g})$.

\section{Entrapment efficiency and drug loading}

Entrapment efficiency and drug loading were calculated based on the concentration of tetrandrine in the beads. Shortly, $30 \mathrm{mg}$ of beads of each formula was precisely weighed, and then dissolved in $10.0 \mathrm{ml}$ of phosphate buffer $\mathrm{pH} 6.8$, then stirred for two hours using a magnetic stirrer at $200 \mathrm{rpm}$ until the beads were swollen and disintegrated. $\mathrm{HCl} 0.5 \mathrm{~N}$ was added to beads solution up to $50 \mathrm{ml}$ and then centrifuged for $15 \mathrm{~min}$ at a speed of $2500 \mathrm{rpm}$. After centrifugation, the supernatant was separated into the flask, and $0.5 \mathrm{~N} \mathrm{HCl}$ was added to it up to $50 \mathrm{ml}$. Seven milliliters of the diluted supernatant was then diluted again in 50.0 $\mathrm{ml}$ volumetric flask with $\mathrm{pH} 6.8$ phosphate buffer solution. The absorbance of dissolved tetrandrine was measured using UV-Vis spectrophotometer at $280 \mathrm{~nm}$, and the concentration of tetrandrine was calculated using the calibration curve of the standard (Iswandana et al., 2017a).

Drug loading was calculated by comparing the measured concentration of tetrandrine and the weight the beads"

$$
\% \text { Drug loading }=\frac{\text { the drug content in beads }}{\text { the weight of beads }} \times 100 \%
$$

Entrapment efficiency (EE) was calculated by comparing the measured concentration of tetrandrine and the initial amount of tetrandrine in the beads of its formula

$$
\% \mathrm{EE}=\frac{\text { the total amount of tetrandrine in beads }}{\text { the initial amount of tetrandrine }} \times 100 \% \text {. }
$$

\section{Swelling test}

The swelling property of the beads was measured by calculating the increased weight of the beads after immersed in phosphate buffer solution $\mathrm{pH}$ 6.8. The weight of the beads was measured at 5, 10, 15, 30, and $60 \mathrm{~min}$

$$
\% \mathrm{SR}=\frac{\mathrm{W} 2-\mathrm{W} 1}{\mathrm{~W} 1} \times 100 \%
$$

where SR = swelling ratio, $\mathrm{W} 1=$ dried weight of beads (initial weight) (g), and W2 = weight of swelling beads (g).

\section{In-vitro release study}

In-vitro release study of tetrandrine from the beads was performed on beads containing in $200.0 \mathrm{ml}$ at $37 \pm 0.5^{\circ} \mathrm{C}$ of the medium $0.1 \mathrm{~N}$ hydrochloric acid $\mathrm{pH} 1.2$ for two hours, phosphate buffer $\mathrm{pH} 7.4$ for three hours and phosphate buffer $\mathrm{pH} 6.8$ for three hours, under stirring speed of $100 \mathrm{rpm}$. Ten milliliters of samples were taken at 15, 30, 45, 60, 90, 120 and $180 \mathrm{~min}$ at each phase, and $10 \mathrm{ml}$ of the medium was immediately added to replace it. The absorbance of dissolved tetrandrine was measured using UV-Vis spectrophotometer at $280 \mathrm{~nm}$, and the concentration of tetrandrine was calculated using the calibration curve of the standard. The percentage of drug released was calculated and plotted over the time

$$
\text { n-minute }=\frac{(y n-a) \times f p \times M}{b \times 1000}+\cdots+\frac{(y 15-a) \times f p \times S}{b \times 1000},
$$

where $y=$ tetrandrine absorption, $y n=$ tetrandrine absorption on minute-n, $f p=$ dilution factor, $M=$ release medium volume, $S=$ sampling volume, $a=$ intercept coefficient, and $b=$ slope.

\section{Experimental animals}

Rats were housed with permanent access to water and food in a temperature-controlled room with a $12 \mathrm{~h}$ ' dark/light cycle regimen before the experiment. The experiments were approved by the Ethical Committee of Cipto Mangunkusumo Hospital, Faculty of Medicine, Universitas Indonesia with ethical approval Reg. No. 319/UN2.F1/ETIK/2015.

\section{In-vivo targeted test}

The best formula of the beads which were coated with HPMCP, CAP, Eudragit L100 or Eudragit L100-55 were tested in-vivo into the rats. The in-vivo targeted test was performed qualitatively to define the beads toleration against gastric and proximal intestine $\mathrm{pH}$ thus could reach the colon. Prior to the experiment procedure, animals have been acclimatized for one week. Rats were placed in the cage with free access to their food and drink. The cage environment was controlled to minimize the humidity and the temperature was maintained at around $25^{\circ} \mathrm{C}$. Furthermore, there was a dark and light cycle every $12 \mathrm{~h}$. Each group of rats was placed in a separate cage and maintained in such a way so the rats did not interact with each other. The condition of the rats was monitored every day and the weight of rats was weighed every week. Rats were divided into two groups: (1) 
$10 \%$ CAP-coated beads, and (2) uncoated-beads as a control. Each group was fed with four beads (Iswandana et al., 2017b). Beads were dispersed in $5.0 \mathrm{ml}$ water and given to the GIT of the rat using a gastric sonde (Prajapati et al., 2008). Two and a half hours after administration of the beads, the rat was sacrificed, and the GIT was observed visually. The beads were considered as successfully targeted into the colon if the beads were found in the colon of the rats.
$\mathbf{A}$

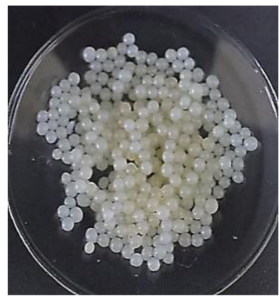

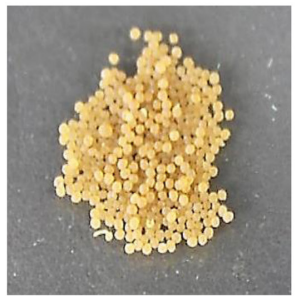

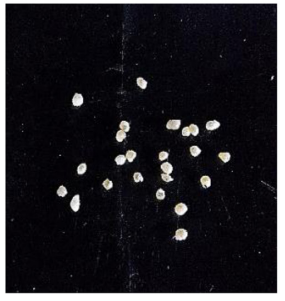

Fig. 1: Beads morphology, (A) wet, (B) dry, and (C) coated.

A

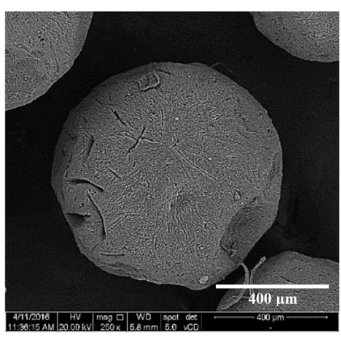

B

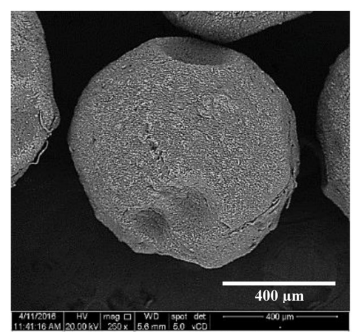

C

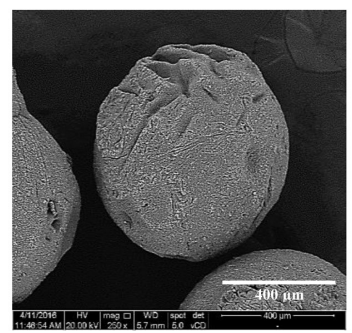

Fig. 2: SEM under 250x magnification, (A) Formula 1, (B) Formula 2, and (C) Formula 3.

\section{RESULTS AND DISCUSSION}

The preliminary study showed that the beads were best prepared by dripping tetrandrine- $\mathrm{HCl}$ in $2 \%$ of sodium alginate solution into 3\% calcium chloride solution and stirring at $200 \mathrm{rpm}$ (Formula 2). This formulation resulted in rigid and spherical shape beads. Coating the core beads with $\mathrm{pH}$-sensitive polymers turned beads into spherical, yellow, and odorless as depicted in Figure 1. Based on SEM results (Figure 2), the beads from Formula 1, 2, and 3 were quite spherical. Under $250 \times$ magnification, the surface of beads had a rough surface, cracks, and pores. These cracks and a rough surface in beads might be caused by a low density of the polymer matrix. It can lead the beads to shrink, and the polymer matrix on the surface will crack during the drying process (Manjanna et al., 2009).

Figure 3 showed that calcium alginate beads loaded by tetrandrine had a shift lower than the melting point of calciumalginate beads without tetrandrine and the tetrandrine itself. The shift of lower melting point demonstrated the occurrence of interaction between the material contained in the beads, i.e., the interaction between sodium alginate, calcium chloride, and tetrandrine. A low melting point also implied that the active substance had been dispersed homogeneously in the polymer. Decreasing in melting point might also indicate that the drug components were in the amorphous state (Pasparakis and Bouropoulos, 2009).

Based on tetrandrine diffractogram (Figure 4A), It demonstrated that tetrandrine had seven positions with a sharp peak in a free state. In contrast, calcium alginate beads loaded by tetrandrine diffractogram (Figure 4B) showed gentler than the tetrandrine diffractogram. We can conclude that there had been a decrease in the degree of crystallinity of the active ingredient which might be due to the active substance had been dispersed in the polymer matrix.

As shown in Table 3, the average diameter and water content of the beads increase with the higher concentration of calcium chloride. The increase concentration in calcium ion will cause the entire area cross-linked in the polymer became full and resulted in a larger bead. The high-water levels in the core beads can be caused by the polymer material. Alginate has hydrophilic properties and its allowed to absorb a certain amount of water (Rajendran and Basu, 2009). Hydrophilic properties of alginate allow the beads to absorb water from moisture during the storage process. Furthermore, the water content of the coated beads was lower than the core beads since coated beads overcome two cycles of the drying process. The result can be seen in Table 4 .

Core beads Formula 2 was considered as the best core beads due to better process yield $(37.56 \%)$ and better entrapment efficiency $(82.46 \%)$ than other formulae, as described in Table 3. In Figure 5, it illustrated that the Formula 1, 2, and 3 were swollen at $390.41 \%, 946.13 \%$, and $1101.76 \%$, respectively. The swelling index of the calcium alginate beads was influenced by the hydration of the hydroxyl group alginate (Pasparakis and Bouropoulos, 2009). When the beads were in phosphate buffer pH 6.8 medium, $\mathrm{Ca}^{2+}$ binding to $\mathrm{COO}^{-}$group at poly-mannuronate residue on alginate so that the water can be absorbed into the beads (Bajpai, 2006). The more $\mathrm{Ca}^{2+}$ connected across with alginate, the higher the ability of the beads to expand. 
Table 3: Characterization of core beads.

\begin{tabular}{|c|c|c|c|c|c|}
\hline Core Beads & Formula & Mean of Diameter $(\mu \mathrm{m})$ & Water content \pm SD* $(\%)$ & Process yield (\%) & Mean of entrapment efficiency $\pm \mathrm{SD}^{*}(\%)$ \\
\hline \multirow{3}{*}{ Calcium alginate beads } & 1 & 733.120 & $17.50 \pm 0.02$ & 36.10 & $78.60 \pm 1.46$ \\
\hline & 2 & 749.580 & $17.72 \pm 0.03$ & 37.56 & $82.46 \pm 2.73$ \\
\hline & 3 & 780.683 & $21.65 \pm 0.04$ & 32.40 & $68.23 \pm 0.60$ \\
\hline
\end{tabular}

$*_{n}=3$.

Table 4: Characterization of coated beads.

\begin{tabular}{|c|c|c|c|}
\hline Beads & Formula & Mean of Diameter $(\mu \mathrm{m})$ & Water content \pm SD $(\%)^{*}$ \\
\hline \multirow{2}{*}{ F2 beads coated by HPMCP } & $2 \mathrm{~A}$ & 902.840 & $6.24 \pm 0.02$ \\
\hline & $2 \mathrm{~B}$ & 924.150 & $5.88 \pm 0.03$ \\
\hline \multirow{2}{*}{$\mathrm{F} 2$ beads coated by CAP } & $2 \mathrm{C}$ & 915.307 & $8.28 \pm 0.02$ \\
\hline & $2 \mathrm{D}$ & 901.027 & $6.24 \pm 0.02$ \\
\hline \multirow{2}{*}{ F2 beads coated by Eudragit L-100-55 } & $2 \mathrm{E}$ & 915.720 & $8.32 \pm 0.04$ \\
\hline & $2 \mathrm{~F}$ & 952.453 & $7.72 \pm 0.06$ \\
\hline \multirow{2}{*}{ F2 beads coated by Eudragit L100 } & $2 \mathrm{G}$ & 913.880 & $6.88 \pm 0.02$ \\
\hline & $2 \mathrm{H}$ & 955.607 & $6.96 \pm 0.02$ \\
\hline
\end{tabular}

$* \mathrm{n}=3$.

Table 5: In-vivo-targeted results.

\begin{tabular}{|c|c|c|c|}
\hline Group & Animal & Beads distance from gastric $(\mathrm{cm})$ & Mean of beads distance \pm SD $(\mathrm{cm})$ \\
\hline & Rat 1 & 65 & \\
\hline \multirow[t]{3}{*}{ Control } & Rat 2 & 68 & $66.7 \pm 1.5$ \\
\hline & Rat 3 & 67 & \\
\hline & Rat 4 & 64 & \\
\hline \multirow[t]{2}{*}{ Calcium alginate beads coated by CAP $10 \%$ (Formula $2 \mathrm{C}$ ) } & Rat 5 & 67 & $64.7 \pm 2.1$ \\
\hline & Rat 6 & 63 & \\
\hline
\end{tabular}

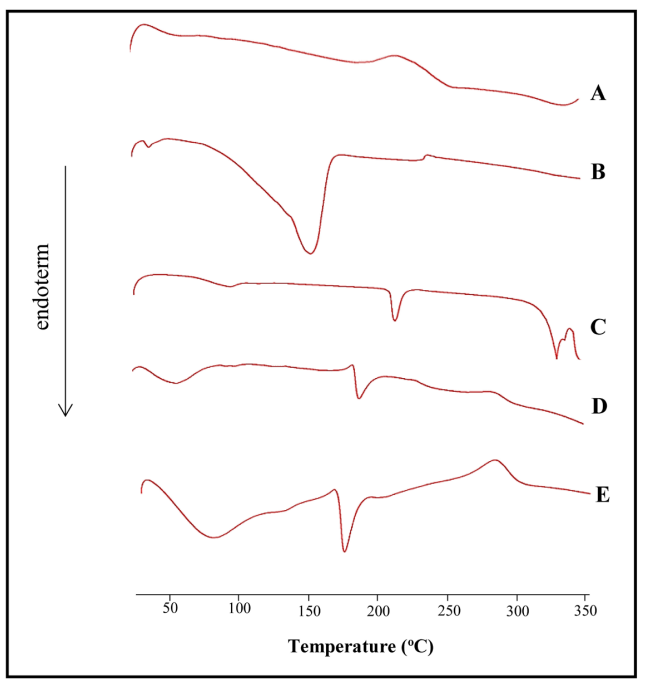

Fig. 3: DSC thermogram, (A) sodium alginate, (B) calcium chloride, (C) tetrandrine, (D) F2 beads without tetrandrine, and (E) F2 beads with tetrandrine.

In-vitro release study was carried out in the $\mathrm{HCl} \mathrm{pH}$ 1.2 medium, phosphate buffer $\mathrm{pH} 7.4$ medium, and phosphate buffer pH 6.8 medium. The chosen media were used to simulate the condition in gastric, small intestine, and colon, respectively. Displacement various media were performed continuously to obtain the release of the drug which depicted the cumulative release of drugs in the body. These cumulative release profiles from each formula are presented in Figure 6.

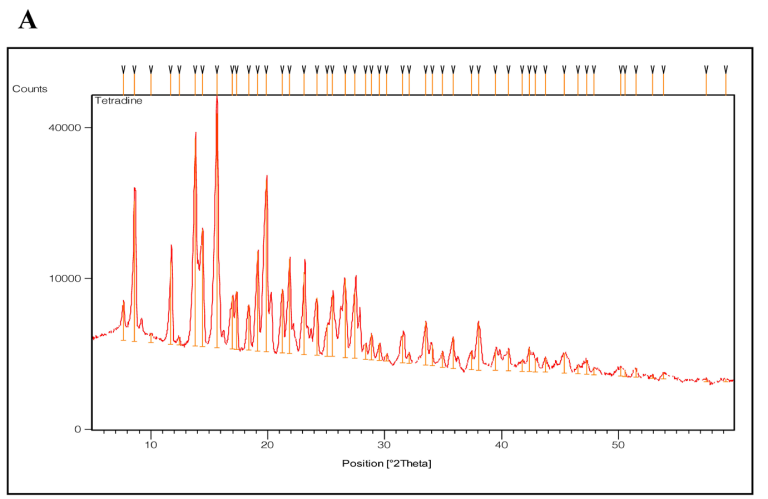

B

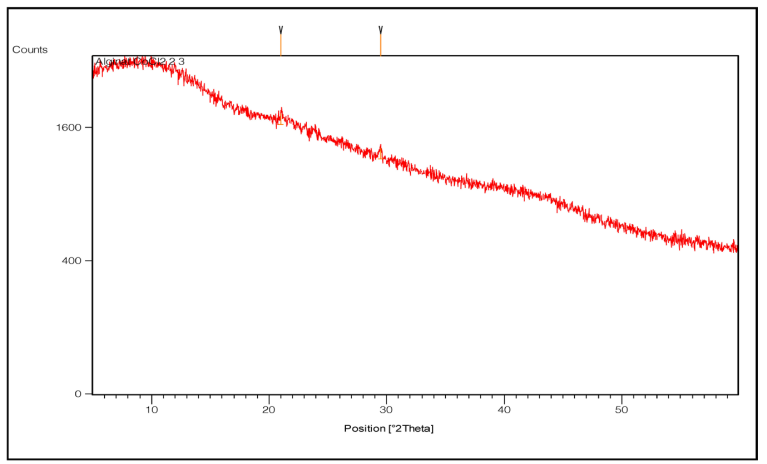

Fig. 4: Diffractogram, (A) tetrandrine and (B) calcium alginate beads with tetrandrine. 


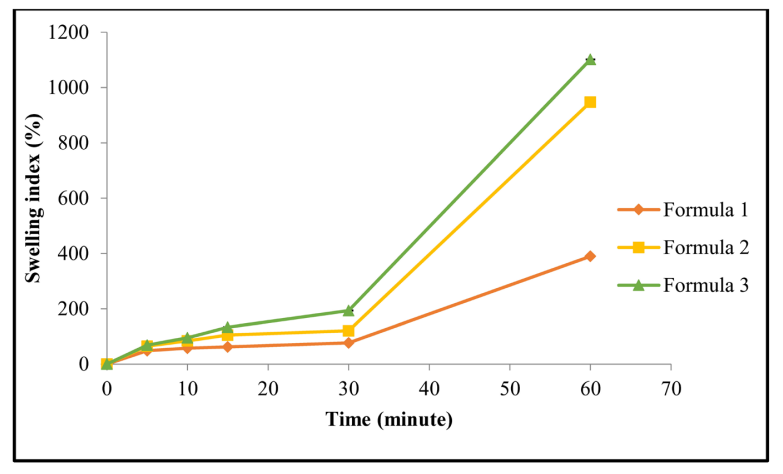

Fig. 5: Swelling index in phosphate buffer $\mathrm{pH} 6.8$.

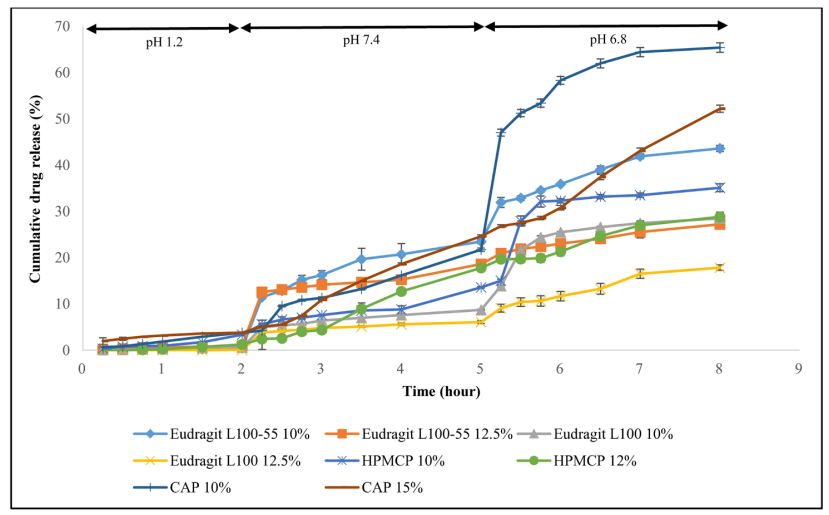

Fig. 6: Cumulative release profiles of calcium-alginate beads coated by Eudragit L100-55/Eudragit L100/CAP/HPMCP in $\mathrm{HCl}$ pH 1.2, phosphate buffer $\mathrm{pH} 7.4$, and phosphate buffer $\mathrm{pH}$ 6.8. Data are expressed as mean $+/-$ SD. $n=3$.

All formulae showed a low release in $\mathrm{HCl} \mathrm{pH} 1.2$ but vary in phosphate buffer $\mathrm{pH} 7.4$ and $\mathrm{pH}$ 6.8. As shown in Figure 6, Formula 2B (HPMCP 12\%) was the best formula to resist the release of tetrandrine in the hydrochloric acid $\mathrm{pH} 1.2$ medium. It showed $1.23 \%$ in a cumulative release. Although Formula 2B had the most excellent property in holding the drug at $\mathrm{pH} \mathrm{1.2,} \mathrm{it}$ only able to release the cumulative drug $31.15 \%$ at the end of the dissolution process. On the other hand, Formula 2C (CAP 10\%)

A

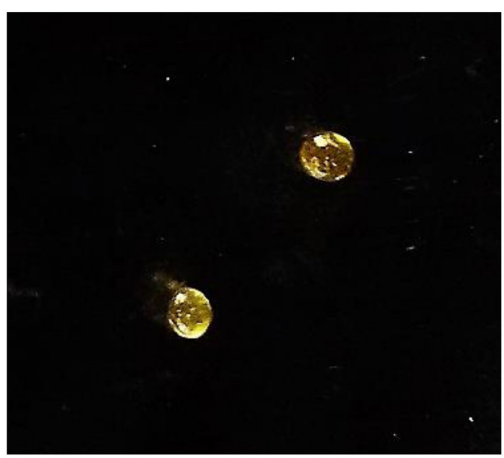

showed the higher released at the end of the dissolution process, $67.68 \%$. Based on these results, Formula $2 \mathrm{C}$ had been chosen for the in-vivo-targeted test.

In vivo-targeted test was performed by following the method from Prajapati et al. (2008) with modification (Prajapati et al., 2008). To check the optimal time of beads transport to the rat colon, we performed a preliminary test. Preliminary beads administration was given by oral, and the gastrointestinal tract was taken out at several interval time variations between $1,1.5$, $2,2.5$, and $3 \mathrm{~h}$. Based on the preliminary result, $2.5 \mathrm{~h}$ had been chosen as the time duration of administered beads.

Four beads from Formula 2C was administered orally to the rat using a gastric sonde. Beads were found on average distance of $64.7 \pm 2.1 \mathrm{~cm}$ from the antrum (Table 5). It indicated that the beads were found in the small intestine (Figure 7). The chosen time duration was no longer enough for colon observation. Control beads (without coating excipient) also showed the same result but a different appearance in the swelling degree. Formula 2C showed no swelling compared to the control (Figure 8). This result suggested that beads which were coated by CAP $10 \%$, was able to hold the drug released in the gastric. Furthermore, this result also in line with the in-vitro release study.

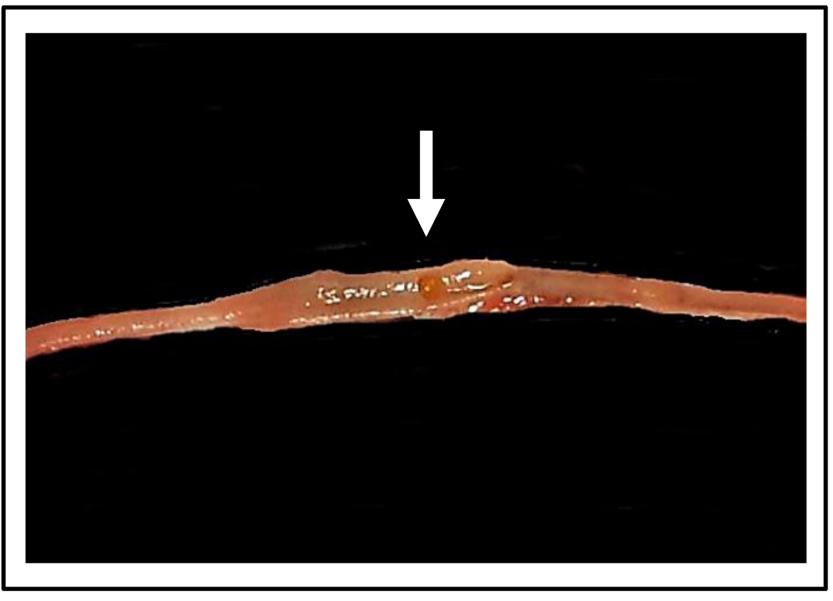

Fig. 7: Beads appearance in rat intestine.

B

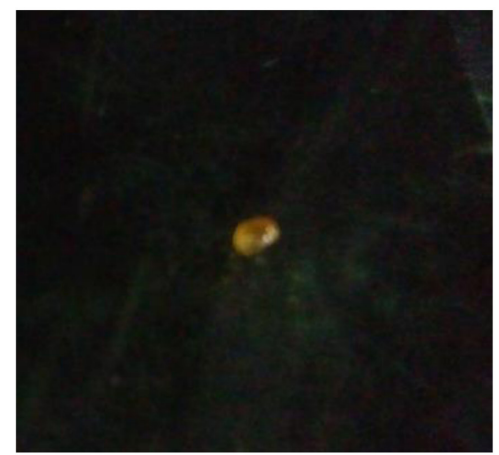

Fig. 8: Beads morphology, isolated from rat intestine, (A) control and (B) coated by CAP $10 \%$. 


\section{CONCLUSION}

Together with all results, it can be concluded that Formula 2 (ratio of sodium alginate and $\mathrm{CaCl}_{2}, 2: 3$ ) was the best formulation to obtain the optimal parameter in producing the beads. Furthermore, beads which were coated with CAP $10 \%$ (Formula 2C) was the best formula to deliver tetrandrine to the colon.

\section{ACKNOWLEDGMENTS}

The authors gratefully thank PT. Jebsen Jessen Ingredients, Indonesia for supplying Eudragit L100 and L10055. Also, the authors acknowledge Dr. Herman J. Woerdenbag and Prof. Dr. Peter Olinga from Department of Pharmaceutical Technology and Biopharmacy, the University of Groningen for their valuable insights.

\section{FINANCIAL ASSISTANCE}

The authors also gratefully acknowledge the financial support for this study by Faculty of Pharmacy, Universitas Indonesia Grant Research: Young Lecturer Research (No. 027/ UN2.F11.D5/HKP.05.00/2016).

\section{CONFLICT OF INTEREST}

The authors have no conflict of interest to declare.

\section{REFERENCES}

Adhyatmika A, Putri KSS, Beljaars L, Melgert BN. The elusive antifibrotic macrophage. Frontiers in Medicine. 2015; 2:1-11.

Amidon S, Brown JE, Dave VS. Colon-targeted oral drug delivery systems: design trends and approaches. AAPS PharmSciTech. $2015 ; 16(4)$.

Bajpai SK. Swelling behavior of barium ions-crosslinked bipolymeric sodium alginate-carboxymethyl guar gum blend beads Reactive \& Functional Polymers. 2006; 66:659-66.

Biswas N, Sahoo RK. Tapioca starch blended alginate mucoadhesive-floating beads for intragastric delivery of metoprolol tartrate. International Journal of Biological Macromolecules. 2016; 83:61-70.

Iswandana R, Pham BT, van Haaften WT, Luangmonkong T, Oosterhuis D, Mutsaers HAM, Olinga P. Organ- and species-specific biological activity of rosmarinic acid. Toxicology in Vitro. 2016; 32:2618 .

Iswandana R, Putri KSS, Sandiata CE, Triani S, Sari SP, Djajadisastra J. Formulation of Tetrandrine Beads Using Ionic Gelation Method Ca-Pectinate Coated pH-Sensitive Polymers as Colon-Targeted Dosage Form. Asian Journal of Pharmaceutical and Clinical Research. 2017a; 10(10):90-5.
Iswandana R, Putri KSS, Dwiputra R, Yanuari T, Sari SP, Djajadisastra J. Formulation of chitosan tripolyphosphate-tetrandrine beads using ionic gelation method: in vitro and in vivo evaluation. International Journal of Applied Pharmaceutics. 2017b; 9(5):109-15.

Lin Z, Zhong S, Liu D, Mao Y, Ning P. Effect of tetrandrine on the TGF- $\beta$-induced smad signal transduction pathway in human hypertrophic scar fibroblasts in vitro. Burns. 2012; 38:404-13.

Loftus EV. Clinical epidemiology of inflammatory bowel disease: Incidence, prevalence, and environmental influences. Gastroenterology. 2004; 126:1504-17.

Luangmonkong T, Suriguga S, Bigaeva E, Oosterhuis D, de Jong KP, Schuppan D, Mutsaers HAM, Olinga P. Antifibrotic efficacy of a TGF- $\beta$ kinase inhibitor on early-onset and end-stage of fibrosis in precision-cut human liver slices. AASLD LiverLearning ${ }^{\circledR}$. 2015; 110678.

Manjanna KM, Shivakumar B, Kumar PTM. Formulation of oral sustained release aceclofenac sodium microbeads. International Journal of PharmTech Research. 2009; 1(3):940-52.

Pasparakis G, Bouropoulos N. Swelling studies and in vitro release of verapamil from calcium alginate and calcium alginate-chitosan beads. International Journal of Pharmaceutics. 2006; 323:34-42.

Philip AK, Philip B. Colon targeted drug delivery systems: a review on primary and novel approaches. Oman Medical Journal. 2010; 25(2):79-87.

Prajapati SK, Tripathi P, Ubaidulla U, Anand V. Design and development of gliclazide mucoadhesive microcapsules: in vitro and in vivo evaluation. AAPS Pharma Sci Tech. 2008; 9(1):224-30.

Rajendran A, Basu SK. Alginate-chitosan particulate system for sustained release of nimodipine. Tropical journal of pharmaceutical research. 2009; 8(5):433-40.

Rathbone MJ, Zealand N, Roberts MS. Modified-release drug delivery technology. New York; 2003 Moffat A. Clarke's analysis of drugs and poisons ( $3^{\text {rd }}$ ed.). London: Pharmaceutical Press; 2004.

Rowe RC, Sheskey PJ, Owen SC. Handbook of pharmaceutical excipients sixth edition. Washington: Pharmaceutical Press and American Pharmacists Association; 2009.

Shukla RK, Tiwari A. Carbohydrate polymers: applications and recent advances in delivering drugs to the colon. Carbohydrate Polymers. 2012; 88(2):399-416.

Speca S, Giusti I, Rieder F, Latella G. Cellular and molecular mechanisms of intestinal fibrosis. World Journal of Gastroenterology. 2012; 18(28):3635-61.

Wynn TA. Cellular and molecular mechanisms of fibrosis. Journal of Pathology. 2008; 214:199-210.

How to cite this article:

Iswandana R, Putri KSS, Wulandari FR, Najuda G, Sari SP, Djajadisastra J. Preparation of Calcium Alginate-Tetrandrine Beads Using Ionic Gelation Method as Colon-Targeted Dosage Form. J App Pharm Sci, 2018; 8(05): 068-074. 